\title{
Dermoid Cyst of the Conus Medullaris in Adult: A Case Report and Review of the Literature
}

\author{
Lakhdar F*, Benzagmout M, Chakour K and Chaoui MF
}

Department of Neurosurgery, University Sidi Mohammed benabdellah, Medical School of fez, Morocco Hassan II Hospital, Morocco

\section{Abstract}

ISSN: 2637-7748

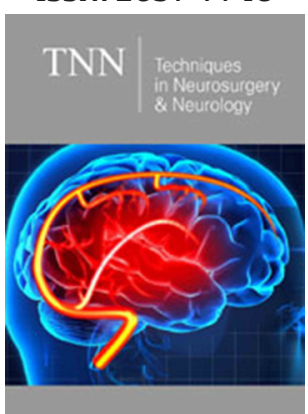

*Corresponding author: Fayçal Lakhdar, Department of Neurosurgery, University Sidi Mohammed benabdellah, Medical school of fez, Morocco Hassan II Hospital, Morocco

Submission: 酱 March 03, 2020

Published: 俔 March 16, 2020

Volume 3 - Issue 3

How to cite this article: Lakhdar $\mathrm{F}$ Benzagmout M, Chakour K, Chaoui MF Dermoid Cyst of the Conus Medullaris in Adult: A Case Report and Review of the Literature. Tech Neurosurg Neurol.3(3). TNN.000562.2020.

DOI: 10.31031/TNN.2020.03.000562

Copyright@ Lakhdar F, This article is distributed under the terms of the Creative Commons Attribution 4.0 International License, which permits unrestricted use and redistribution provided that the original author and source are credited.
Background: Intramedullary dermoid cyst is a type of rare congenital intraspinal lesions especially those located in the conus medullaris and not associated with spinal dysraphism. The Management of DC is especially difficult in eloquent areas such as the conus medullaris, with tendency to recurrence and poorly respond to oncologic treatment.

Objective: We aim to provide a summary of the pathology, clinical presentation, and management strategies of dermoid cysts involving the conus medullaris with review of the literature.

Case presentation: A 37-year-old woman presented with progressive low back pain and loss of bowel and bladder function. His magnetic resonance imaging (MRI) scan showed a heterogeneous tumor with tethering of the spinal cord. He was taken for a midline myelotomy that drained yellowish keratinous fluid and decompressed the cyst. No aggressive attempt at complete resection of the cyst wall was undertaken. She made a complete recovery after surgery with complete resolution of her symptoms.

Conclusion: Dermoid cyst of the conus medullaris without any congenital spinal dysraphism make this case unique. Surgical control and restraint are the key for optimal management and good recovery.

Keywords: Dermoid cyst; Conus medullaris; Spinal tumor; Intramedullary

Abbreviations: DC: Dermoid Cyst; MRI: Magnetic Resonance Imaging

Introduction

Dermoid cysts of the conus medullaris are exceptionally rare, accounting for $0.8-2 \%$ of all intraspinal tumors $[1,2]$. They are slow-growing benign tumors that occur primarily due to the defective closure of the neural tube, during the process of development, manifesting in the second and third decades of life. Furthermore, DC are frequently present insidiously, uncommonly seen in clinical practice often pose unique technical surgical challenges and potentially significant morbidity due to the strong adherence to the surrounding spinal cord tissue $[3,4]$ make a complete resection of the cyst wall problematic. Therefore, management is especially difficult for theses tumors involving highly eloquent areas such as the conus medullaris.

\section{Case Report}

A 37-year-old woman presenting with low backache, and progressive weakness of both lower limbs for 5 months. On clinical examination, she had features of a conus medullaris syndrome with grade 4 power in both lower limbs, positive Babinski sign bilaterally, while abdominal reflexes and anal tone were normal without tuft of hair or a patent dermal sinus tract. A magnetic resonance imaging MRI showed cord expansion at the tip of the conus medullaris with a heterogeneous lesion hyperintense on $\mathrm{T} 1$ and hypointense on $\mathrm{T} 2$ images. In addition, contrast enhanced images with gadolinium revealed an intramedullary lesion at T12 L1 segment (Figure 1). After laminectomy, a midline myelotomy was performed and revealed a whitish and yellowish mass with a well-defined adherent capsule to spinal tissue followed by micro-dissection of the cyst wall allowing complete removal of caseous cystic contents with adequate conus decompression (Figure 2). Pathological examination confirmed the diagnosis of dermoid tumor, showing stratified squamous epithelial cells with underlying fibrous connective tissue containing hair follicles, keratin and sebaceous glands. The patient recovered well from the procedure, her back pain had not recurred, and she remained independent postoperatively. 


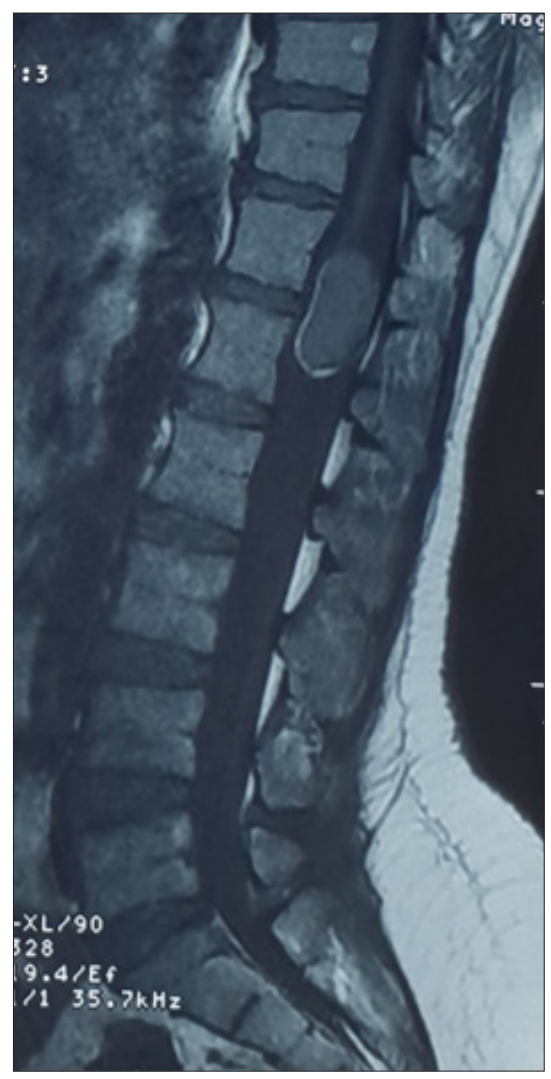

Figure 1a:

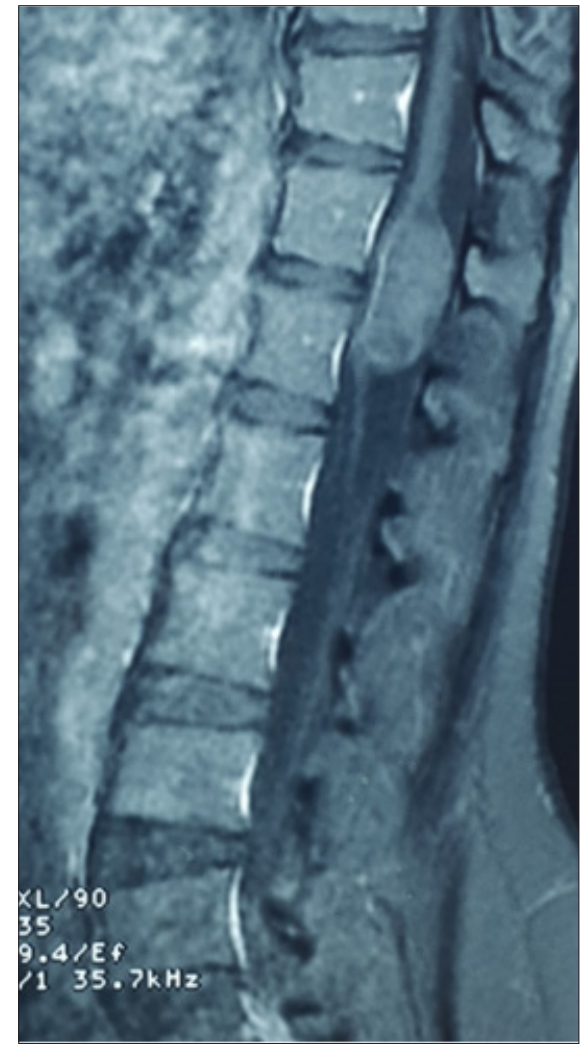

Figure 1b:

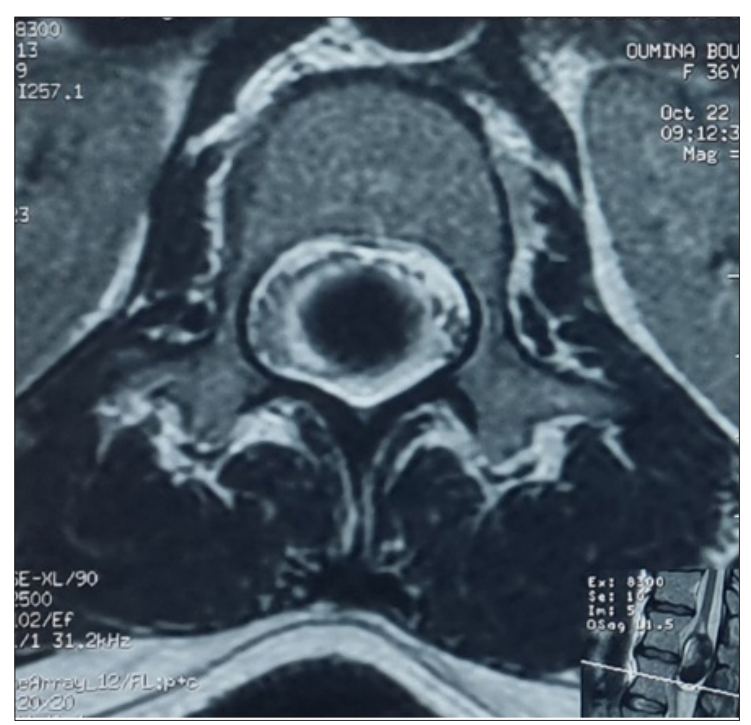

Figure 1c:

Figure 1: Spinal MRI sagittal T1 (a), T1 postcontrast (b) and axial T2 (c) showing an heterogenous lesion hyperintense $\mathrm{T} 1$, hypointense $\mathrm{T} 2$ of the conus at T12 L1 level.

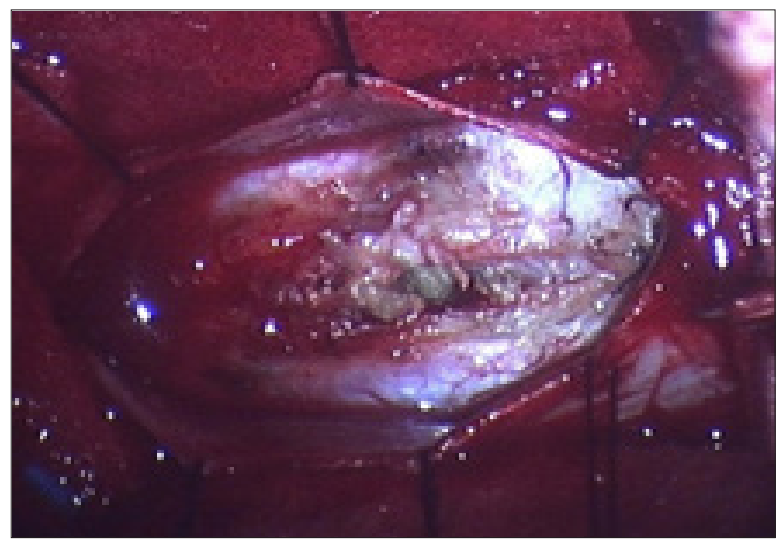

Figure 2: Operative picture showing the midline myelotomy with expression of the keratinous sebaceous content of the cyst (black arrow).

\section{Discussion}

\section{Epidemiology, histology and pathophysiology}

Dermoid cysts are rare and benign tumors that occur within the central nervous system [3-6]. They are located most frequently at the lumbosacral spine, with $60 \%$ of lesions occurring in the conus or the cauda equina [7]. Although conflicting reports, this disease appears to be a slight male predominance, and affecting young active individuals with tendency to recur [8]. Described as "pearly tumors" by Verratus and Cruveilhier [9,10], DC contain dermal, epidermal elements and a dermal sinus tract. On microscopy, these tumors are usually surrounded by a multi-layered cornified epithelium, with pockets of keratin, inclusions of cholesterol crystals, collagen stroma and occasional hair follicles and sebaceous 
glands $[3,4]$. They often have a single cystic component with loose islands of keratin, and cutaneous appendages such as hair follicles, hair, sebaceous and sweat glands, as well as sebum [11-13]. The most widely accepted theory according to the "developmental theory" is that the DC arises from the cell rests that result from defective closure of the neural tube between the third and fourth week of fetal life. In addition, "traumatic theory" was supported by several authors as well as iatrogenic cases have been reported, usually associated with congenital lesions, such as spina bifida and dermal sinus.

\section{Clinical presentation and imaging}

The intramedullary manifestation of DC is an exceptionally rare occurrence and the clinical presentation can vary widely with the location, extent, and consistency of the tumor. They are often silent and discovered fortuitously, although, their presentation can be insidious, or deeply fulminant if they rupture. Some lesions may cause mass effect and creating worsening radicular pain or slowly neurological deficits for a long period. Others can present acutely cauda equina symptoms such as was observed in our case who present portray the typical evolution of spinal dermoid cysts. This case gives an excellent clinical picture of a spinal intramedullary dermoid cyst without signs of spinal dysraphism's. In the other hand, the rupture of the tumor with the migration of fatty particles and cholesterol crystals within the subarachnoid space to the level of the foramina of Luschka and Magendie may often cause obstructive hydrocephalus, seizures, cerebral vasospasm, coma and even sudden death $[7,14,15]$ MRI represents the test of choice in demonstrating intramedullary lesions and made the diagnosis of DC easier, although they can still mimic other lipid-laden tumors. These lesions are usually hyperintense on T1-weighted due to their high cholesterol and fat content as reported in our case, while the T2 signal can vary from hypo to hyper-intense depending on the fluid content of the cyst $[3,4]$. However, low signal on both T1 and T2 weighted images occasionally occurs.

\section{Treatment and outcome}

Typically, in intramedullary dermoid cysts, the capsule adheres to the cord and adjacent neural tissue and attempts at complete resection are totally hazardous [15]. Thereby, most neurosurgeons tend to recommend a conservative approach to avoid iatrogenic neurological injury, especially in critical areas such as the conus medullaris or cauda equine $[13,14,15]$. So, how aggressive to be with resection of intramedullary DC in surgery? The best strategy still a fine balance between relative operative caution and maximum safe resection bearing in mind a very high recurrence rate regardless of what is done, and this lesion may require repeated surgery and close observation [10]. However, it is extremely important to be cautious during surgical resection, as a rupture can lead to severe consequences. Although after incomplete removal, cyst recurrence occurs many years after first surgery and does not justify the risk involved in attempting total capsule resection and tumoral remnants, specifically the stratified epithelial membrane surrounding tissue. Furthermore, Suocheng et al. [2] recommended placement of an intraspinal Ommaya reservoir after a complete resection of cyst wall, which may help to delay and minimize clinical symptoms by aspiration of cystic contents in case of recurrence [2]. Also, the presence of residual cyst wall might be the cause of dermoid cyst recurrence. However, in recurrent cases, intrathecal chemotherapy could be promising pending results in clinical practice $[4,15]$. Radiotherapy was reported as well with reduction of the secretions from the dermoid cyst wall and might delay or prevent cyst recurrence [16]. Finally, the outcome varied among different authors, preoperative neurological status conditions a chance of improvement.

\section{Conclusion}

Dermoid cysts of the conus medullaris are rare benign tumors that can present challenges in surgical resection and management. Their benign nature makes it tempt for the surgeon to want to achieve a complete resection. Otherwise, surgical control and restraint are the key for optimal management and good recovery. However, further prospective studies with longer follow-up and larger samples are needed to strengthen these conclusions.

The Patient Consent Statement: Patient consent has consented to the submission of the case report for submission to the journal.

\section{References}

1. Banna M, Talalla A (1975) Intraspinal dermoids in adults. Br J Radiol 48(565): 28-30.

2. Suocheng G, Yazhou X (2014) A review on five cases of intramedullary dermoid cyst. Childs Nerv Syst 30: 659-664.

3. Maio PN, Mikulis DJ, Kiehl TR, Guha A (2012) Airp best cases in radiologic-pathologic correlation: spinal conus dermoid cyst with lipid dissemination. Radiographics 32(4): 1215-1221.

4. Garg K, Kumar R (2014) Isolated central canal rupture of spinal dermoid. report of 3 cases. J Neurosurg Spine 21(3): 361-366.

5. Calabro F, Capellini C, Jinkins JR (2000) Rupture of spinal dermoid tumors with spread of fatty droplets in the cerebrospinal fluid pathways. Neuroradiology 42: 572-579.

6. Karadag D, Karagulle AT, Erden A, Erden I (2002) MR imaging of a ruptured intraspinal dermoid tumour with fat droplets in the central spinal canal. Australas Radiol 46(4): 444-446.

7. Graham DV, Tampieri D, Villemure JG (1988) Intramedullary dermoid tumor diagnosed with the assistance of magnetic resonance imaging. Neurosurgery 23(6): 765-767.

8. Falavigna A, Righesso O, Teles AR (2009) Concomitant dermoid cysts of conus medullaris and cauda equina. Arq Neuropsiquiatr 67(2A): 293296.

9. Van GJC, Schwartz HG (1967) Growth of dermoids from skin implants to the nervous system and surrounding spaces of the newborn rat. J Neurosurg 26(1): 14-20.

10. Aoun SG, Liu MA, Still M, El Ahmadieh TY, Tamimi MA, et al. (2018) Dermoid cysts of the conus medullaris: clinical review, case series and management strategies. J Clin Neurosci 50: 247-251.

11. Karaaslan B, Ulku G, Ucar M, Demirdag TB, Inan A, et al. (2016) Intramedullary dermoid cyst infection mimicking holocord tumor: should radical resection be mandatory? a case report. Childs Nerv Syst 32(11): 2249-2253. 
12. Lee JK, Kim JH, Kim JS, Kim TS, Jung S, et al. (2001) Cervical dermal sinus associated with dermoid cyst. Childs Nerv Syst 17: 491-493.

13. Sandalcioglu IE, Gasser T, Asgari S, Lazorisak A, Engelhorn T, et al. (2005) Functional outcome after surgical treatment of intramedullary spinal cord tumors: experience with 78 patients. Spinal Cord 43(1): 34-41.

14. Tekkok IH (2008) Intramedullary epidermoid cysts. J Neurosurg Spine 8: 202-203.
15. Najjar MW, Kusske JA, Hasso AN (2005) Dorsal intramedullary dermoids. Neurosurg Rev 28(4): 320-325.

16. Bristow RG, Laperriere NJ, Tator C, Milosevic M, Wong CS (1997) Postoperative radiotherapy for recurrent dermoid cysts of the spine: a report of 3 cases. J Neurooncol 33(3): 251-256.

For possible submissions Click below:

Submit Article 